\title{
WOUNDS OF THE KNEE-JOINT.
}

BY ALFRED HOSMER, M. D.

"Wounds made into the cavities of large joints are the most dangerous of those affecting the body almost in any instance." - AstLey CoOper, 1818.

"When a large joint is opened, even by a small incised or punctured wound, there is great danger lest such extensive local mischief and constitutional disturbance ensue as to lead to the destruction of the articulation, with loss of the patient's life."- Erichsen, 1857.

"The opening of the synovial sac, with escape of synovia, even if the wound be not large, is always a severe injury, often interfering with the function of the joint, and not unfrequently dangerous to life."-BrLLROTH, 1877.

Case I. A farmer's son, twelve years old, while chopping wood, made a button-hole in the synovial membrane of the left knee, outside of and a little below the patella. The opening easily admitted the tip of the forefinger. The wound, a clean one, was closed with sutures, a compress moistened with cold water was applied, and absolute rest was enjoined. No trouble of any importance, local or general, followed; within a reasonable time perfect recovery took place. The boy now has no reason to regret the carelessness with which he inflicted upon himself the wound.

CASE II. A carpenter, of good constitution and habits, in the fourth decade of life, while at work one summer's afternoon upon the roof of a building, by the careless use of a shingling hatchet opened one of his knee-joints. He knew nothing of surgical traditions, and his courageous philosophy enabled him to look with contempt upon any casualty incident to his trade, which apparently left only an incision of moderate length in the skin. He completed the work of the day as if nothing had happened. But before going to bed there occurred to him the propriety of having some professional assistance.

The clothing, which was thick and heavy, was extensively saturated with synovial fluid. The hæmorrhage had been slight, although the wound was quite a long one. The plan of treatment proposed will readily suggest itself. The patient cheerfully accepted everything advised, excepting the injunction to keep still. The second day afterward he returned to his labor, in spite of my protest, and lost no more time. Convalescence was uninterrupted, and the recovery of the knee was complete.

Case III. A boy, twelve years old, while playing with a hatchet, inflicted a short wound over the internal condyle of the right knee. He at once walked a large fraction of a mile in search of his mother. She returned with him, and resorted to the methods which are in accord with the principles of domestic medicine. I was not called until the early part of the second week. There were then well-marked constitutional symptoms. The limb was much swollen from the groin to the 
toes, and was hot and tender. The joint was distended with a wellmarked effusion, and was also the seat of considerable pain. Being satisfied that the original wound had penetrated the cavity of the knee, $I$ at once reopened and enlarged it, and also made a second opening on the opposite side over the external condyle. A sero-purulent fluid escaped. This was the starting-point of a convalescence which advanced in a most satisfactory way, and terminated in complete recovery, leaving the joint just as good as ever.

In this case we undoubtedly had what surgical writers have accepted as a condition of safety, namely, the immediate closing by adhesion of the aperture in the synovial membrane; yet that process did not avert an inflammatory action. When the patient came to my hands his danger lay in the fact that he did not have an incision that penetrated into the cavity of his knee.

CASE IV. A man somewhat over thirty years of age came several miles to consult me at my office. His antecedents in respect of sanitary conditions and morbid processes were not of the best. A few hours before he had penetrated his right knee-joint with the dull blade of an old pocket-knife, and a rough-looking instrument it was. He had seen no reason for discontinuing the use of the limb, and acted accordingly. The joint was somewhat swollen. By forcible flexion he could eject from the wound, in a stream of considerable size and force, synovial fluid, which in its quantity could be measured in teaspoonfuls. A silver wire suture was passed, and the usual directions and precautions were given. He thought that he could not release his knee from its accustomed work, and certainly did not very long. I saw the case but once. I am assured by a brother of the patient that no trouble followed the accident.

CASE V. A young man, not of a healthy family, while working at his trade wounded himself with a chisel. Two and a half centimetres above the upper margin of the patella was a transverse cut four centimetres long externally, and in its deep portion making an opening somewhat shorter into the knee-joint. The wound was closed with metallic sutures, and rest in bed faithfully maintained. There followed a moderate effusion into the joint, but this was not of many days' duration. The only constitutional disturbance was, on the third day, an elevation of the temperature to $100^{\circ} \mathrm{F}$. The amount of discomfort referred to the knee was trifling, and everything proceeded in a most satisfactory manner.

CASE VI. To the foregoing series I might add one taken from the veterinary branch of our art. A colt, three years old, when running loose in an inclosure, was suddenly found to be lame. Marked swelling of one knee, as it is called, attracted attention, and led to the discovery of a puncture, which entered the cavity of the joint. No particular trouble ensued; the limb was very soon as good as ever. 
These cases occurred in a country practice, and make up the sum of the writer's experience in injuries of this kind. He has never happened to meet an instance of disastrous termination. Sume of the cases here reported were treated before the value of carbolic assistance was generally known; before the precepts of Lister had explained and enforced the importance of the antiseptic idea, and had defined for it an efficient method of application. No one of them was managed upon a strictly antiseptic plan, hut they all did well simply because there did not occur in them that bad quality and dangerous tendency with which such wounds are commonly accredited, rightly or wrengly. The results obtained are in striking contrast with the doctrines of those authorities whom I have quoted.

\section{RECENT PROGRESS IN OPHTHALMOLOGY.}

BY O. F. WADSWORTH, M. D.

Eserine and Atropine in Glaucoma. - The experience of various oculists in the use of eserine, as brought out in the debate on glatcoma at the meeting of the Heidelberg society ${ }^{1}$ is of interest. Schweigger warned against its too free use, since it might easily excite iritis. I Laqueur had found it effective in cutting short light attacks of acute glancoma, or in the prodromal attacks. Its efficacy in more severe attacks appeared doubtful, but it is of use in producing, by contraction of the pupil, a condition more fayorable for the performance of iridectomy. In glaucoma simplex its action is not to be relied on. The opinion that it causes decrease of tension in the anterior chamber through pressure backward by the iris, ${ }^{2}$ or that which refers this effect to the freeing of adhesions at the periphery of the iris, ${ }^{2}$ is negatived by the fact that, in certain cases, the tension is diminished, the arterial pulse ceases, before the pupil begins to contract. Follicular catarh of the conjunctiva is sometimes excited by prolonged use of eserine, of like character to that occasionally produced by atropine. Cohn believed it of value in enabling the postponement of operation for a day or two in acute cases; in a chronic case, where there were reasons to prevent operation, he had employed it for a year, but the field had continued to narrow, the vision to decrease. Pfluger had found by the tonometer, in a case of glaucoma simplex with intermittent inflammation, tension increased twenty minutes after the use of eserine. Knapp, in one case of acute glaucoma, had relieved the attack by eserine, and had no return at the end of five months; in other acute cases the good effect was only temporary. In subacute glaucoma the effect was uncertain, in clrronic either negative or positively harmful; in one such case it brought on

1 Berichte ueber die 11 te Versammlung der ophthal. Ges., Heidelberg, 1878.

2 JoURNAL, vol. xevi., pages 528, 529. 